\title{
Nonlinear Multigrid solver exploiting AMGe Coarse Spaces with Approximation Properties
}

\author{
Christensen, Max la Cour ; Villa, Umberto; Engsig-Karup, Allan Peter; Vassilevski, Panayot
}

Publication date:

2016

Document Version

Publisher's PDF, also known as Version of record

Link back to DTU Orbit

Citation (APA):

Christensen, M. L. C., Villa, U., Engsig-Karup, A. P., \& Vassilevski, P. (2016). Nonlinear Multigrid solver exploiting AMGe Coarse Spaces with Approximation Properties. Abstract from 14th Copper Mountain Conference on Iterative Methods, Copper Mountain, Colorado, United States.

http://grandmaster.colorado.edu/ copper/2016/abstract/christensen_max097106/

\section{General rights}

Copyright and moral rights for the publications made accessible in the public portal are retained by the authors and/or other copyright owners and it is a condition of accessing publications that users recognise and abide by the legal requirements associated with these rights.

- Users may download and print one copy of any publication from the public portal for the purpose of private study or research.

- You may not further distribute the material or use it for any profit-making activity or commercial gain

- You may freely distribute the URL identifying the publication in the public portal 
nt

Next: About this document ...

\title{
Max la Cour Christensen \\ NONLINEAR MULTIGRID SOLVER EXPLOITING AMGe COARSE SPACES WITH APPROXIMATION PROPERTIES
}

\author{
Baunehøjvej 15 st tv \\ 2800 Kongens Lyngby \\ Denmark \\ max@maxlacour.com \\ Umberto Villa \\ Allan P. Engsig-Karup \\ Panayot Vassilevski
}

The paper introduces a nonlinear multigrid solver for mixed finite element discretizations based on the Full Approximation Scheme (FAS) and element-based Algebraic Multigrid (AMGe). The main motivation to use FAS for unstructured problems is the guaranteed approximation property of the AMGe coarse spaces that were developed recently at Lawrence Livermore National Laboratory. These give the ability to derive stable and accurate coarse nonlinear discretization problems. The previous attempts (including ones with the original AMGe method), were less successful due to lack of such good approximation properties of the coarse spaces. With coarse spaces with approximation properties, our FAS approach on unstructured meshes has the ability to be as powerful/successful as FAS on geometrically refined meshes. For comparison, Newton's method and Picard iterations with an inner state-of-the-art linear solver are compared to FAS on a nonlinear saddle point problem with applications to porous media flow. It is demonstrated that FAS is faster than Newton's method and Picard iterations for the experiments considered here. Due to the guaranteed approximation properties of our AMGe, the coarse spaces are very accurate, providing a solver with the potential for mesh-independent convergence on general unstructured meshes.

- About this document ...

nt 留 previc

Next: About this document ...

root 2016-02-22 